\title{
Nutritional care in motor neurone disease/ amyotrophic lateral sclerosis
}

\author{
Assistência nutricional nas doenças do neurônio motor/esclerose lateral amiotrófica \\ Cristina Cleide dos Santos Salvioni', Patricia Stanich², Claudinéa S. Almeida ${ }^{3}$, Acary Souza Bulle Oliveira ${ }^{4}$
}

\begin{abstract}
Patients with amyotrophic lateral sclerosis (ALS) often present changes in nutritional status. Based on weight loss and on difficulty in nutritional management, this study aims to review the different possibilities and to present guidelines concerning nutritional treatment to such patients. Diet characteristics, types of treatment and nutritional therapy indicating administration routes and discussing the details of the disease are described herein. Nutritional therapy has been a substantial therapeutic resource for ALS development.
\end{abstract}

Keywords: nutritional assessment, nutrition, gastrostomy, amyotrophic lateral sclerosis, motor neuron disease.

\section{RESUMO}

Pacientes com esclerose lateral amiotrófica (ELA) frequentemente apresentam alteração do estado nutricional. Baseado na perda ponderal de peso e na dificuldade no manejo nutricional, o objetivo desse estudo é rever as estratégias de tratamento nutricional para a manutenção do estado nutricional desses doentes. Nesse trabalho, descrevem-se as características da dieta, as formas de tratamento e terapia nutricional com indicação das vias de administração, bem como discuti-se as particularidades da doença. A terapia nutricional tem se mostrado um recurso terapêutico primordial atuante na evolução da ELA.

Palavras-chave: avaliação nutricional, nutrição, gastrostomia, esclerose lateral amiotrófica, doença do neurônio motor.

Motor neuron diseases (MNDs) are a group of neurodegenerative clinical syndromes characterised by neuronal death in motor cortex, brainstem and ventral horn of the spinal cord. Amyotrophic lateral sclerosis (ALS) is the most common of the MNDs, defined by the progressive degeneration of upper and lower motor neurons, and causes atrophy, fasciculation, weakness and spasticity ${ }^{1,2}$. The natural course of ALS can be defined as death from respiratory failure ${ }^{3}$. The prevalence rate of ALS currently is 2.7-7.4 per 100,000 inhabitants; the incidence is 1.9 per 100,000 inhabitants 4 .

The aetiology of ALS is not fully clarified; however, excitotoxicity from glutamate neurotransmitter, changes in immunity, deficiency of neurotrophic factors, physical traumas, persistent viral infections and even environmental factors has been suggested as possible causes of the disease ${ }^{5,6}$.
During the course of ALS, nutritional status (NS) declines, and is often inadequately treated in clinical practice, Although various studies confirm the correlation between decrease in body weight and body mass index as negative predictors of survival ${ }^{7-9}$. Some factors are inherent to the amendments to the NS and the reduction of food intake in patients with it, such as: loss of appetite, dysphagia, dyspnea, depression and hypermetabolism ${ }^{10-12}$. Hypermetabolism origin and development in ALS have not been thoroughly elucidated; $50 \%$ of these patients, however, present in hypermetabolic state ${ }^{11}$ causing the increased nutritional needs make the nutritional treatment even more complex.

The disease affects bulbar muscles of patients first, from $25 \%$ to $30 \%$, resulting in progressive dysphagia and leading to decrease in food and hydric intake ${ }^{13}$. The need for modifying

\footnotetext{
Escola Paulista de Medicina, Universidade Federal de São Paulo and Associação Brasileira de Esclerose Lateral Amiotrófica, Sao Paulo SP, Brazil; ${ }^{1}$ Nutricionista, Pós-Graduanda do Departamento de Neurologia, Escola Paulista de Medicina, Universidade de São Paulo, Sao Paulo SP, Brazil;

${ }^{2}$ Nutricionista, Doutora em Ciências, Escola Paulista de Medicina, Universidade de São Paulo, Sao Paulo SP, Brazil;

${ }^{3}$ Nutricionista do Ambulatório Médico Especialidades, Hospital Santa Marcelina, Sao Paulo SP, Brazil;

${ }^{4}$ Professor Afiliado, Departamento de Neurologia, Escola Paulista de Medicina, Universidade de São Paulo, Sao Paulo SP, Brazil; Correspondence: Cristina C. S. Salvioni; Rua Felipe Antunes 187; 02270-040 São Paulo SP - Brasil; E-mail: cris.salvioni@gmail.com Conflict of interest: There is no conflict of interest to declare.

Received 25 November 2012; Received in final form 02 August 2013; Accepted 09 August 2013.
} 
diet consistency contributes to reduction of high-value foodprotein energy. In analysis of food intake, found that only one of sixteen patients studied presented appropriate recommendations for front intake energy ${ }^{9}$.

Malnutrition, common with progression of disease, muscle strength and breathing capacity due to weakening as well as increase the relative risk of death ${ }^{13,14,15}$.

Meet the energy requirements of macro and micronutrients, adjust degree of dysphagia brought and indicate enteral nutritional therapy at right time have been the subject ${ }^{9,11,16}$. Within this context, this present review aims to present nutritional treatment strategies for the maintenance of NS of ALS patients.

\section{DIAGNOSTIC CRITERIA}

The nutritionists working in the Neuromuscular Disorders Unit, Department of Neurology and Neurosurgery, Escola Paulista de Medicina, Universidade Federal de São Paulo developed the protocol herein.

Based on the El Escorial ${ }^{17}$, firstly, we guided the patients by neurological assessment and diagnostic confirmation; secondly, by assessing the nutrition team.

\section{Nutritional evaluation method}

The assessment of nutritional status before the conduct adopted and is composed the clinical history, anthropometric measurements, food history and laboratory tests.

\section{Anthropometric parameters}

Weight, height, arm circumference (AC), tricipital skinfold (TSF), arm muscle circumference (AMC), arm muscle area (AMA) and arm fat area (AFA) are the anthropometric parameters considered.

The ideal body weight for each individual is defined according to the table of Metropolitan Life Insurance Company ${ }^{18}$. Such parameter guides nutritional therapy once some patients do not know how to relate their normal weight. The percentage of weight loss (\% WL) is determined according to the equation: \% WL=(normal weight $(\mathrm{kg})$ - current weight $(\mathrm{kg}))$ / normal weight $(\mathrm{kg})$. Where: normal weight=weight reported by the patient before the disease onset; current weight=patient weight on the assessment date Individuals with \% WL from 5\% to $10 \%$ are considered malnourished; those with $\% \mathrm{WL}$ over $10 \%$ are considered severely malnourished ${ }^{19}$.

The stature is measured in meters $(\mathrm{m})$. We estimated the stature for patients unable to walk based on the equations proposed by Chumlea et $\mathrm{al}^{20}$.

The anthropometric index adopted to classify the nutritional status is the body mass index (BMI), obtained by dividing weight by the square of height and expressed as $\mathrm{kg} / \mathrm{m}^{2}$. Nutritional status is classified into four categories: malnutrition BMI $<18.5$ for age $<60$ years and BMI $<22$ if age $\geq 60$ years; eutrophy or normality if $18.5 \leq \mathrm{BMI}<25$ if age $<60$ years and $22 \leq$ BMI if age $<27 \geq 60$ years; overweight if $25 \leq \mathrm{BMI}<30$ if age $<60$ years and $27 \leq \mathrm{BMI}<30$ if age $\geq 60$ years; obesity if $\mathrm{BMI} \geq 30 \mathrm{Kg} / \mathrm{m}^{2} 21,22$.

Arm measurements performed are: AC and TSF. Concerning the AC, is expressed in centimeters and measured at the midpoint between the acromion process of the scapula and the olecranon. We measured the TSF in millimeters by using a calliper. From AC and TSF, we obtained AMC, AMA and AFA. Considering as reference the work of Frisancho, we assessed AC, TSF, AMC, AMA and $\mathrm{AFA}^{23}$.

\section{Food intake assessment}

Food anamnesis is evaluated of reminder. Obtaining detailed dietary historyu target the appropriate nutritional intervention through individualized therapy through analysis of energy and intake of macro and micronutrients.

\section{Laboratory tests}

The analysis of laboratory tests also makes up nutritional evaluation. When compared to the clinical signs, nutritional status can vary slowly, showing that biochemical analysis is valid, however, the results should be interpreted with caution. The biochemical data requested are: lipid profile, sodium, potassium, serum iron, ferritin, transferrin, phosphorus, total protein and serum albumin, fraction, and protein linked to retinol.

Amyotrophic lateral sclerosis functional rating scale

Every nutritional assessment is applied the assessment scale motor and functional skills (amyotrophic lateral sclerosis functional rating scale - ALSFRS-R) ${ }^{24}$. As a tool, ALSFRS-R monitors disability progression in ALS patients and consists of 12 items that assess the self-sufficiency levels of patients in areas involving nutrition, self-care, ambulation, communication, dyspnea, orthopnea and ventilatory support requirement. Each item is classified according to a scale from zero to four points. The lower the score, more severe is the disease.

\section{Nutrition intervention}

The identification of nutritional status through diagnostic methods leads to the formulation of a plan to deal with each situation individually.

After analysis of medical history, dietary, anthropometric and biochemical data, in addition to the application of ALSFRS-scale $\mathrm{R}$ is prescribed food plan and held the dietary guidance to patient. The frequency of monitoring is carried every 3 months. The care process is continuous, so the goals are reworked so that the revaluation is determined if there have been changes in diagnosis or condition affecting the patient's nutritional risk.

Nutritional treatment protocol can be found in the Figure. 


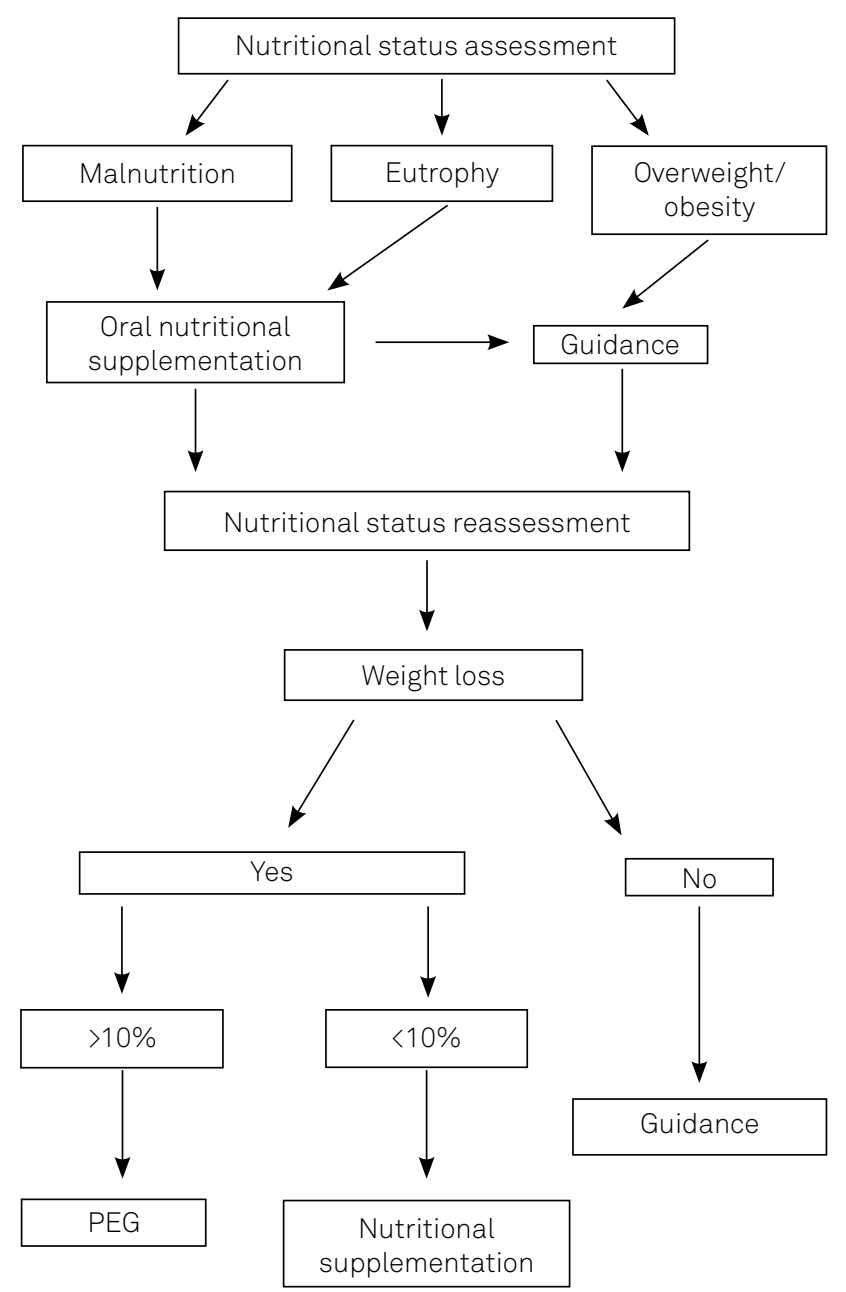

Figure. Protocol concerning nutritional care and treatment adopted for patients with amyotrophic lateral sclerosis or motor neurone disease, treated in the Department of Research on Neuromuscular Diseases, Paulista School of Medicine. São Paulo, 20117.

\section{NUTRITIONAL RECOMMENDATIONS AND NUTRITIONAL THERAPY}

\section{Dietary Prescription}

Nutritional therapy applied to ALS aims to supply the nutritional needs for all stages of disease progression, minimise protein catabolism, ensure oral feeding and indicate early nutritional support.

Generally, more fractionation, high-calorie, high-protein, normolipidic, high-fibre, nutrient unchanged, adequate water supply and ideal consistency against dysphagia are characteristics of the diet-oriented treatment.

\section{Energy needs}

To estimate energy requirements, the equation of Harris and Benedict ${ }^{25}$ is used with the current weight, including the proposed factors, activity and injury, for chronic diseases, Long et $\mathrm{al}^{26}$.

\section{Protein}

The calculation of protein requirements is based on the recommendations of the Brazilian Society of Food and Nutrition ${ }^{27}$, being offered $1.0 \mathrm{~g}-1.2 \mathrm{~g}$ protein $/ \mathrm{kg}$ in current weight/day. Food intake, source of high biological value protein, should be highlighted, comprising roughly $70 \%$ in total protein intake per day.

\section{Carbohydrates}

The diet is oriented normoglycidic (50-60\% of total energy intake) and modified to hypoglycemic, specifically for patients with abnormal oxygen saturation. For these cases, the energy supply must be maintained at the expense of lipids, with high-fat diets ( $>35 \%$ of total energy intake).

\subsection{Lipids}

It is recommended ingesting $25-35 \%$ of total energy intake, considering $\leq 7 \%$ saturated fatty acids, $\leq 10 \%$ polyunsaturated fatty acids and $\leq 20 \%$ monounsaturated fatty acids ${ }^{28}$.

\subsection{Fibres}

The fibre intake gradually restricts itself in the course of the disease, worsening dysphagia. Cooking food is necessary for a suitable consistency limitation, ensuring that its consumption is not excluded from diet.

Adding cereal flour to porridge, orange juice with papaya and dried pitted prunes, liquefied food, boiled and mashed vegetables and legumes cooked well are preparations easy to swallow and help intestinal transit.

When adequate intake of fibres becomes impossible, supplemental fibre with module containing industrialized mix of soluble and insoluble fibres is necessary.

According to the age and sex of the individual, 25-38 $\mathrm{g}$ of dietary fibre intake per day is recommended ${ }^{29}$.

\section{Water}

At times, when dysphagia signals occur, liquid must be thickened to reduce the aspiration risk and offer the proper water requirement to patients. The use of industrialised thickeners grants a more suitable consistency to liquid, however, excessive consumption can worsen constipation. Gelatin, with or without flavour, can also be used as a means to modify food consistency.

Food with high liquid content, e.g. fruit and vegetable puree, fruit juice and smoothies assist in hydration and reaching the estimated water requirement of $30-40 \mathrm{~mL} / \mathrm{kg} / \mathrm{day}^{30}$.

\section{Micronutrients}

The micronutrient prescription follows the recommendations of dietary intake recommended according to age and sex of patients ${ }^{31-34}$.

The summary of dietary prescription is in Table. 


\begin{tabular}{lcc}
\hline Nutritional assessment & & Dietary guidance \\
\hline Body mass index & Largest fractionation & Short interval between meals \\
Arm circumference & High caloric & Harris and Bennedict ${ }^{25}+$ activity factor + injury factor \\
Tricipital skinfold & Adequate carbohydrates & $50-60 \%$ total calories \\
Arm muscle circumference & High protein & 1,0 a $1,2 \mathrm{~g} / \mathrm{kg}$ per day \\
Arm muscle area & Appropriate in lipidis & $25-35 \%$ total calories \\
Percentage of weight loss & High-fiber & $25-38$ g per day \\
Laboratory tests & Vitamins and minerals & Recommended dietary allowance \\
Exames laboratoriais & Water & $30-40 \mathrm{ml} / \mathrm{kg}$ per day \\
\hline
\end{tabular}

\section{Nutritional therapy}

Nutritional therapy entails early detection of inefficient food intake, need for modifying the diet consistency and early indication of alternative diet, which includes probes or ostomies (gastrostomy or jejunostomy).

\section{Nutritional treatment on dysphagia}

The diet-oriented treatment is set up to facilitate swallowing, optimise nutritional intake and lessen aspiration risk. The defined food viscosity and texture must be correlated to the degree of dysphagia presented, hence changes in consistency and feeding time include: general diet, with more time to perform the meal; supervised, aided and bland diet; and supervised soft diet with actions to protect swallowing. In general, diet there is no restriction upon food consistency, prescribed for patients without swallowing complaints. Bland diet shows low levels of cellulose and connective tissue, softened by cooking or mechanical action. In soft diet foods are softened by cooking and liquefied in cream consistency. Patients requiring changes in the food consistency should receive nutritional and clinical monitoring, since the total daily food offered can be qualitatively and quantitatively inadequate to supply the needs of such patients, making supplementation necessary.

Adjusting the diet is indicated to suit the nutritional value of the diet and ensure energy intake when consuming certain foods becomes inefficient. For individuals presenting a weight loss $\geq 10 \%$ in normal weight or malnutrition is prescribed industrial protein, energy product, included in the dietary habits, aiming for values from $100 \%$ to $130 \%$ of the individual dietary recommendations ${ }^{16}$.

\section{Enteral nutritional therapy}

The indication criteria of percutaneous endoscopic gastrotomy (PEG) considers clinical monitoring based on the indicators for multidisciplinary assessment, which includes: nutritional assessment, emphasising the drop in $10 \%$ of body weight in the last three months; presence of dysphagia; and respiratory function assessment, highlighting forced vital capacity (FVC) measurement for nearly $50 \%$ of what was predicted $^{35}$. Limitation for PEG placement is observed in patients with moderate respiratory risk. In such cases, to insert radiologic gastrostomy is proposed, whose method resembles PEG, either between complications during and after the procedure or in survival of patients ${ }^{36}$.

The calliper of the gastrostomy tube shown is preferably $24 \mathrm{Fr}$ to facilitate diet infusion with different viscosities. Nutritional therapy can consist of hand-crafted, industrialized or mixed diet and consider social, economic aspects for therapy of choice. Complications of enteral nutritional therapy may occur and should be rigorously assessed. Diarrhoea is common and can cause electrolyte imbalance, worsening the nutritional status of patients. In this wise, the main causes are: bacterial contamination, diet hyperosmolarity, infusion rate, drug therapy, high-fat diet and low-fibre diet. To decrease this condition, it is advisable to administer the diet in speed and concentration according to patient tolerance, adding soluble fibres and reviewing drug therapy with medical staff.

By using a syringe (bolus), the homemade-enteral diet administration or gravitational administration can be performed. The indication of the infusion method should be based on patient status, type of diet, nutritional needs and concomitant oral feeding.

Bolus infusion is to infuse $200-300 \mathrm{~mL}$ syringe diet with 20 $\mathrm{mL}$ or $60 \mathrm{~mL}$ every three hours, slowly infusing with minimal pressure on the syringe plunger. In gravitational administration, the infusion is free, leaving it flowing by means of the equipment, driven only by gravity. It is accomplished by enteral feeding bottle or bag and equipment, connected to the probe of patient. The bottle is placed on movable support at a height above the head of the patient.

Regardless of the administration chosen, the chest of the patient must be raised to at least $30^{\circ}$ during and after one hour the diet infusion, to prevent gastroesophageal reflux and provide more comfort for patients. The probe should be flushed in $60 \mathrm{~mL}$ medium volume of potable water after the administration of each diet for cleaning the probe and hydration.

\section{IMPORTANT CLINICAL CHARACTERISTICS}

The absence of specific methods for nutritional assessment of ALS patients shows the need to integrate clinical 
history, anthropometric measurements, food history and laboratory tests for classification of nutritional status and monitoring of adopted. The BMI, adopted as one of the indicators of nutritional status in our service, has often been used $^{7,12,37}$. The reduction of one (1) $\mathrm{kg} / \mathrm{m}^{2}$ from the normal weight would be associated with a $20 \%$ mortality risk ${ }^{7}$.

For more precise information on body composition, anthropometry of skinfold measures with arm and circles has proven to be a valuable tool for identification of malnutrition. In comparative analysis of nutritional status assessment between electrical bioimpedance and anthropometry significant differences between the methods, in which anthropometric measures per se would be enough to body composition analysis, were not observed ${ }^{16,38}$. Anthropometry can perhaps reflect both the nutritional status and the loss of motor neurons. Both situations, however, are liable to be influenced and may contribute to disease progression ${ }^{37}$.

The execution of food recall puts patients in touch with the measurement of appetite, food exclusion, food intake, quantities ingested, mealtimes and intervals between meals. The advantages to use would be the easy, low cost and when carried out in series provide estimates of usual intake ${ }^{39}$.

The decrease in food intake by loss of appetite, dysphagia, weakness, dyspnea, decline in ability to self-care and depression $^{37}$ that culminates in nutritional status depletion brings the need to rescue or preserve the individual's pleasure in eating with harmonic presentation plates in color, texture, consistency and temperature, in order to increase its palatability. Food habits and preferences, socioeconomic status and any environmental factors connected to food must be considered to achieve nutritional goals.

The equation of Harris and Benedict ${ }^{25}$ with factors for calculation of energy needs ${ }^{26}$ is suggested as a replacement in cases where indirect calorimetry is impossible ${ }^{40}$. Despite the discrepancies in the current literature and the lack of knowledge on the actual energy requirements of these patients, one can assume that continuously assessing food intake, weight gain or weight loss and body composition may help to treat and individualise energy requirements. It is worth mentioning that reductions equal to or greater than usual at moment weight $5 \%$ diagnosis increase at twice the risk of death when compared to patients with stable or loss weight less than $5 \%$, which reinforces the concept of dont induce weight loss in ALS even in cases of overweight.

Hyperproteic diet oriented, with 1.0 to 1.2 gprotein $/ \mathrm{kg} /$ day, aims to minimize protein catabolism. In cases of inadequate dietary intake protein modulation is indicated, however, it should be pointed out that supplementation with branched chain amino acids (l-Leucine, l-valine, l-isoleucine) is contraindicated in ALS treatment. Double-blind study investigating the effect of branched-chain amino acids was interrupted due to mortality and decline in forced vital capacity of patients of group under tratament ${ }^{41}$. Concerning supplementation with carnitine and creatine, there were no human studies with clear evidence ${ }^{42}$.

The distribution of total caloric value carbohydrates of diet is normoglycidic (50-60\% of total energy intake). The need for modifying food consistency leads individual to opt for foods associated with greater comfort in time to swallow that, generally speaking, are more rich in carbohydrates which, in some cases, to the worsening of constipation, common disorder in these patients as a result of involvement of abdominal and pelvic muscles, combined with physical inactivity, drug treatment and low intake of fibres ${ }^{43}$. The excessive consumption of carbohydrates can also collaborate with decrease in insulin and glucose intolerance has found in ALS patients ${ }^{44}$. Neurodegenerative diseases can cause neuroendocrine dysfunction that can influence progression of neurodegenerative process ${ }^{45}$. It is not uncommon to observe abrupt elevation on lipid profile. Even in these cases, the diet is maintained. Furthermore, with the limitation period between $25-35 \%$ of total energy intake, and nutritional recommendations dont involve replacing dairy products by skimmed and whole decrease in consumption of food of animal origin. Dupuis et $\mathrm{a} \mathrm{l}^{46}$ observed that dyslipidemia plays a protective factor for disease progression over 12 months in the survival of such patients. Suggested treatments to control dyslipidemia may meddle in ALS progression.

Some patients adopt alternative treatments through selfmedication with micronutrients, especially because the accumulation of free radicals and oxidative stress have been proposed as factors that contribute to progression of disease. A systematic review selected all randomised or quasi-randomised studies controlled in treatment with antioxidants in ALS, i.e. Cochrane Neuromuscular Disease Group Trials register (August 2005), MEDLINE (from January 1996 to August 2005), EMBASE (from January 1980 to August 2005), showed insufficient evidence for the efficacy of using antioxidants to treat such patients. Although there is not substantial evidence from clinical trials to support the clinical use of antioxidants, there is no contraindication ${ }^{47}$.

Initial treatment of dysphagia in ALS patients is based on changes in consistency, viscosity, temperature and presentation of food, fractionation and action to facilitate and protect $^{48}$. Nutritional therapy adopted early can prevent the depletion of physical stocks, in reducing the body fat lean body mass loss inherent to disease. In cases where there is intense weight loss, dysphagia and FVC with values close to $50 \%$ predite is considered an enteral nutrition ${ }^{35}$. In ALS, the indication of PEG is the sovereign comparing to other forms to access digestive tract for nutrition ${ }^{9,49,50}$; moreover, it is an alternative to administrate fluids and medicines with oral feeding, when possible.

The caliber of PEG, preferably 24 french, collaborates with management of diet in different viscosities making it possible diet. The traditional diet is indicated for patients in monitoring, 
more by economical aspect than nutritional quality of the preparation. In any case, as these patients usually do not present digestive or absorptive disorders, using nutrients in its intact form (as with fresh food) brings no inconvenience ${ }^{49}$.

\section{FINAL CONSIDERATIONS}

Patients with ALS have presented risk to nutritional status. Thus, we highlight how important is the need for early and systematic nutritional intervention for these patients, considering:
1. Maintaining nutritional status, since the nutritional aspect is a prognostic factor for survival in these patients.

2. Performing anthropometric assessment and contemplating food intake periodically.

3. Individualising energy requirements during the course of the disease.

4. Ensuring the maintenance of oral feeding without risk of bronchoaspiration with change in consistency.

5. Minimising protein catabolism with the appropriate supply of macronutrients and micronutrients.

6. Indicating early nutritional therapy to improve quality of life.

\section{References}

1. Chieia M A, Oliveira ASB, Silva HCA, Gabbai AA. Amyotrophic lateral sclerosis: considerations on diagnostic criteria. Arq Neuropsiquiatr 2010;68:837-842.

2. Oliveira ASB, Pereira RDB. Amyotrophic lateral sclerosis (ALS). Three letters that change the people's life for ever. Arq Neuropsiquiatr 2009;67:750-782.

3. Rowland LP, Shneider NA. Amyotrophic lateral sclerosis. N Engl J Med 2001;344:1688-1700.

4. Worms PM. The epidemiology of motor neuron diseases: a review of recent studies. J Neurol Sci 2001;191:3-9.

5. Silva HAC. Etiopatogenia da ELA: causa única ou várias causas? Ver Neurociências 2006;14(Suppl eletrônico) - abr/jun.

6. Ahmed A, Wicklund MP. Amyotrophic lateral sclerosis: what role does environment play? Neurol Clin 2011;29:689-711.

7. Marin B, Desport JC, Kajeu P, et al. Alteration of nutritional status at diagnosis is a prognostic factor for survival of amyotrophic lateral sclerosis patients. J Neurol Neurosurg Psychiatry 2011;82:628-634.

8. Desport JC, Preux PM, Truong CT, et al. Nutritional assessment and survival in ALS patients. Amyotroph Lateral Scler Other Motor Neuron Disord 2000;1:91-96.

9. Kasarskis EJ, Berryman S, Vanderleest JG, Schneider AR, McClain CJ. Nutritional sclerosis: status of patients with amyotrophic relation to the proximity of death. Am J Clin Nutr 1996;63:130-137.

10. Slowie LA, Paige MS, Antel JP. Nutritional considerations in the management of patients with ALS amyotrophic lateral sclerosis. J Am Diet Assoc 1983; 83:44-47.

11. Bouteloup C, Desport JC, Clavelou P, et al. Hypermetabolism in ALS patients: an early and persistent phenomenon. I Neurol 2009;256:1236-1242.

12. Desport JC, Preux PM, Magy L, et al. Factors correlated with hypermetabolism in patients with amyotrophic lateral sclerosis. Am J Clin Nutr 2001;74:328-334.

13. Mitsumoto H, Davidson M, Moore D, et al. Percutaneous endoscopic gastrostomy (PEG) in patients with ALS and bulbar dysfunction. Amyotroph Lateral Scler Other Motor Neuron Disord 2003;4:177-185.

14. Desport JC, Preux PM, Truong TC, Vallat JM, Sautereau D, Couratier P. Nutritional status is a prognostic factor for survival in ALS patients. Neurology 1999;53:1059-1063.

15. Braun MM, Osecheck M, Joyce NC. Nutrition assessment and management in amyotrophic lateral sclerosis. Phys Med Rehabil Clin N Am 2012;23:751-771.

16. Stanich P, Pereira AML, Chiappetta ALML, Nunes M, Oliveira ASB, Gabbai AA. Suplementação nutricional em pacientes com doença do neurônio motor/ esclerose lateral amiotrófica. Rev Bras Nutr Clin 2004;19:70-78.
17. El escorial revisited: revised criteria for the diagnosis of ALS. World Federation of Neurology research group on motor neuron diseases. A consensus conference held at Airlie House, Worrenton, 1998, Virginia, April 2-4.

18. Grant JP, Custer PB, Thurlon J. Current techniques of nutrition assessment. In Handbook of total parenteral nutritional. Philadelphia, Saunders, 1980

19. Mahan K, Stump SE. Krause: alimentos, nutrição e dietoterapia. Ed.11. São Paulo:Roca,2005:535-569

20. Chumlea WC, Roche AF, Steinbaugh ML. Estimating stature from knee height for persons 60 to 90 years of age. J Am Geriatric Soc 1985; 33:116-120.

21. World Health Organization. Physical status: the use and interpretation of anthropometry. Technical Report Series n 854. Geneve; 1995.

22. White JV, Dwyer JT, Possner BM, Ham RJ, Lipschitz DA, Weekmen NS. Nutrition screening iniciative: development and implementation of the public awareness checklist and screening tools. J Am Diet Assoc 1992; 92:163-167.

23. Frisancho AR. Anthropometric standards for assessment of growth and nutritional status. Ann Arbor, University of Michigan, Press, 1990: 185.

24. Kaufmann P, Levy G, Thompson JLP, et al. The ALSFRSr predicts survival time in an ALS clinic population. Neurology 2005; 64: 38-43.

25. Harris JA, Benedict FG. A biometric study of basal metabolism in man. Washington, DC: Carnegie Institute of Washington, 1919.

26. Long CL, Schaffe, N, Geiger JW. Metabolic response to injury and illness: estimation of energy and protein needs from indirect calorimetry and nitrogen balance. JPEN 1979;3:452-456.

27. Vanucchi H, Menezes EW, Campana AO, Lajolo, FM. Aplicações das recomendações nutricionais adaptadas à população brasileira. Ribeirão Preto, Editora Legis Suma, 1990.

28. IV Diretrizes brasileiras sobre dislipidemia e prevenção de aterosclerose do Departamento de Aterosclerose da Sociedade Brasileira de Cardiologia. Arq Bras Cardiol 2007:88(Suppl 1):2-19.

29. Institute of medicine. Dietary reference intakes for energy, carbohydrate, fiber, fat, fatty acids, cholesterol, protein, and amino acids. Washington (DC): National Academy Press, 2005

30. Kreymann K, Berger MN, Deuts N, Hies-mayra M, Jolliet P, Kazandjiev G. Guideline for the use of parenteral and enteral nutrition in adult and pediatric patients. Section VI: Normal requirements - adults. JPEN 2002;26 (Suppl 1): S22-S24.

31. Institute of Medicine. Dietary reference intakes for vitamin A, vitamin $\mathrm{K}$, arsenic, boron, chromium, copper, iodine, iron, manganese, molybdenum, nickel, silicon, vanadium and zinc. Washington (DC): National Academic Press; 2002. 
32. Institute of Medicine. Dietary reference intakes for vitamin C, vitamin E, selenium and carotenoids. Washington (DC): National Academy Press; 2002.

33. Institute of Medicine. Dietary reference intakes for calcium, phosphorus, magnesium, vitamin D, and fluoride. Washington, (DC): National Academy Press; 1999.

34. Institute of Medicine. Dietary reference intakes for thiamin, riboflavin, niacin, vitamin B6, folate, vitamin B12, pantothenic acid, biotin, and choline. Washington (DC): National Academic Press; 1998.

35. Silani V. Nutrition in ALS. European ALS health profile study 2000;9:1-3.

36. Blondet A, Lebigot J, Nicolas G, et al. Radiologic versus endoscopic placement of percutaneous gastrostomy in amyotrophic lateral sclerosis: multivariate analysis of tolerance, efficacy and survival. J Vasc Interv Radiol 2010; 21:527-533.

37. Worwood AM, Leigh PN. Indicators and prevalence of malnutrition in motor neurone disease. Eur Neurol 1998;40:159-163.

38. Diaz EO, Villar J, Immik M, Gonzales T. Bioimpedance or antropometry? Eur J Clin Nutr 1988;43:128-137.

39. Fisberg RM, Marchioni DML, Colucci ACA. Avaliação do consumo alimentar e da ingestão de nutrientes na prática clínica. Arq Bras Endocrinol Metab 2009;53:617-624.

40. Genton L, Viatte V, Janssens JP, Héritier AC, Pichard C. Nutritional state, energy intakes and energy expenditure of amyotrophic lateral sclerosis (ALS) patients. Clin Nutr 2011; 30:553-559.

41. Cameron A, Rosenfeld J. Nutritional issues and supplements in amyotrophic lateral sclerosis. Curr Opin Clin Metab Care 2002;5:631-643.
42. Patel BP, Hamadeh MJ. Nutritional and exercise-based interventions in the treatment of amyotrophic lateral sclerosis. Clin Nutr 2009;28:604-617.

43. Leigh PN, Ray-Chaudhuri K. Motor neuron disease. J Neurol Neurosurg Phychiatry 1994;57:886-896.

44. Hubbard RW, Will AD, Peterson MD, Sanchez A, Gillan WW, Tan SA. Elevated plasma glucacon in amyotrophic lateral sclerosis. Neurology 1992;42:1532-1534.

45. González De Aguilar JL, René F, Dupuis L, Loeffler JP. Neuroendocrinology of neurodegenerative diseases. Insights from transgenic mouse models. Neuroendocrinology 2007;78:244-252.

46. Dupuis L, Corcia P, Fergani A, et al. Dyslipidemia is a protective factor in amyotrophic lateral sclerosis. Neurology 2008; 25; 70:1004-1009.

47. Richard WO, Lane Russell JM, Ross M. A systematic review of antioxidant treatment for amyotrophic lateral sclerosis/motor neuron disease. Amyotroph Lateral Scler 2008;9:195-211.

48. Heffernan C, Jenkinson C, Holmes T, et al. Nutritional management in MND/ALS patients: an evidence based review. Amyotroph Lateral Scler Other Motor Neuron Disord 2004:5:72-83.

49. Stanich P. Relevância dos aspectos nutricionais na sobrevida de pacientes com doença do neurônio motor. Tese de Doutorado. Universidade Federal de São Paulo - Escola Paulista de Medicina. São Paulo, 2011.

50. Andersen PM, Borasio GD, Dengler R, et al. EFNS task force on management of amyotrophic lateral sclerosis: guidelines for diagnosing and clinical care of patients and relatives. Eur J Neurol 2005;12:921-938. 